\title{
The removal of foreign body ingestion in the upper gastrointestinal tract: a retrospective study of 1,182 adult cases
}

\author{
Xin Wang", Shuai Su\#, Yiming Chen, Zelan Wang, Ying Li, Junjie Hou, Weilong Zhong, Yuming Wang, \\ Bangmao Wang
}

Department of Gastroenterology and Hepatology, General Hospital of Tianjin Medical University, Tianjin, China

Contributions: (I) Conception and design: X Wang, S Su; (II) Administrative support: Y Wang, B Wang; (III) Provision of study materials or patients: Y Chen, Z Wang; (IV) Collection and assembly of data: X Wang, Y Li, J Hou, W Zhong; (V) Data analysis and interpretation: X Wang; (VI) Manuscript writing: All authors; (VII) Final approval of manuscript: All authors.

"These authors contributed equally to this work.

Correspondence to: Yuming Wang; Bangmao Wang. Department of Gastroenterology and Hepatology, General Hospital of Tianjin Medical University, Tianjin 300052, China. Email: yumingwangbest@163.com; mwang02@tmu.edu.cn.

\begin{abstract}
Background: Foreign body $(\mathrm{FB})$ ingestion in the gastrointestinal tract is a common and urgent problem observed in children and adults. However, there may be difficulty locating FBs and complications associated with their removal. This study aimed to identify risk factors and complications correlated to the presence and removal of FBs.

Methods: This 5-year retrospective study enrolled 1,311 patients between June 2014 and April 2019. Demographic and endoscopic data were collected, containing age, gender, types and location of FBs, duration of FB ingestion, accessory devices, endoscopic methods, and complications. Logistic regression analysis was applied to evaluate the predictive risk factors.

Results: Among 1,131 patients, FBs were found in 90.16\% of cases. A major predictor for the presence of FB was a presentation of less than 24 hours (h). The types of FBs were jujube pits $(36.72 \%)$ and fish bones (22.00\%), and over $80 \%$ of the FBs were discovered in the esophagus. Complications were found in 239 cases (20.22\%), of which hemorrhage $(162 / 239,67.78 \%$ ) was the most frequent. Age $\geq 60$, duration $\geq 24$ h, and FBs ingested in the esophagus were considered as risk factors for developing complications.

Conclusions: In conclusion, the longer duration, age $\geq 60$, and impaction in the esophagus were risk factors for developing complications following the ingestion of FBs. These factors should be considered when developing assessment and treatment plans in the management of FB ingestion.
\end{abstract}

Keywords: Foreign body ingestion; endoscopy; upper gastrointestinal tract; complication; risk factors

Submitted Jan 27, 2021. Accepted for publication Mar 16, 2021.

doi: $10.21037 /$ atm-21-829

View this article at: http://dx.doi.org/10.21037/atm-21-829

\section{Introduction}

Foreign body $(\mathrm{FB})$ ingestion is a common and urgent problem presenting to gastroenterology (GI) departments and is defined as swallowing anything purposely or unintentionally, including food, medication, toys, coins or other objects (1). An American survey reported the estimated annual incidence of FBs ingestion was 120,000 cases (2). In those patients, most ingestions were linked to dining, whilst others were associated with psychiatric disorders, alcohol dependence, drug abuse, digestive diseases (including achalasia of the cardia), or other abnormal conditions (3-5). The majority of ingested FBs (80-90\%) pass through the GI tract spontaneously andonly $10-20 \%$ require endoscopic intervention and $<1 \%$ need surgery (6-9). Endoscopy has become the preferred choice to remove FBs not only because it avoids the need for surgery, but because it uses conveniently accessible technical devices and advanced visualization, may simultaneously diagnosis 
other diseases, and is cost efficient in comparison to other methods (10-12). However, FBs may not be discovered in every procedure $(13,14)$ and the detection rate may be as low as $75 \%$. Older age and early presentation have been shown to be independent predictors for the presence of FBs $(15,16)$, and occasionally, FB ingestion in the upper-GI tract may cause severe complications, such as perforation, internal bleeding or death (17). According to a previous study (18), an average of 1,500 people died from FBs ingestion each year in the United States. Moreover, most researchers agree that the types, sizes, and the duration of impaction were considered as risk factors linked with complications $(12,19,20)$. This retrospective study aimed to identify factors correlated to the presence of FBs as well as complications associated with their presence and removal, such that timely and appropriate treatments may be applied for patients with FB ingestion. We present the following article in accordance with the STROBE reporting checklist (available at http://dx.doi.org/10.21037/atm-21-829).

\section{Methods}

\section{Patients}

This retrospective study was conducted in the Department of the Gastroenterology, Tianjin Medical University General Hospital. A total of 1,438 patients presenting with suspected FBs between June 2014 and April 2019 were included. Patients with capsule endoscopies and stents, repeated endoscopies, and others whose FBs were extracted from the lower GI tract were excluded from the study. Eventually, the study enrolled 1,311 adult patients (781 women and 530 men) ranging from 18 to 89 years of age and with a mean age of $54.27 \pm 3.03$ years. This study was approved by the Institutional Review Board of Tianjin Medical University General Hospital (Ethical No. IRB2020-WZ-141). All procedures performed in this study involving human participants were in accordance with the Declaration of Helsinki (as revised in 2013). Individual consent for this retrospective analysis was waived.

\section{Endoscopic procedures}

The vital signs, temperature, breathe, pulse and blood pressure should be recorded for every patients. And a physical examination focused on the patient's general condition and was to assess signs of any complications (21). Before the foreign-body extraction procedure, plain chest radiography, or abdominal radiography if there was a suspicion of a gastric or duodenal foreign body. Upper GI endoscopy was performed in each patient under topical pharyngeal anesthesia using lidocaine, or general anesthesia using propofol or ketamine. Flexible endoscopes (mainly GIF-Q260 and GIF-Q290; Olympus Optical Co, Ltd, Tokyo, Japan) were adopted. Devices used included foreign body forceps, snare, rat-tooth forceps, basket, biopsy forceps, and alligator jaws forceps. A snare was used to extract irregular objects such as dental prostheses or metallic FBs and a latex protector hood or a transparent cap was utilized to avoid damage to the GI tract during endoscopic procedures.

\section{Data collection}

Demographic data including age, gender, clinical data containg history of other diseases, time from ingestion to presentation to the emergency department, and endoscopic data recording types, location of $\mathrm{FBs}$, duration of FBs ingestion, endoscopic devices, the methods of anesthesia, and complications were collected for analysis.

\section{Statistical analysis}

$T$ tests were used to compare the mean and standard deviation, Chi-square tests were to contrast proportions, and logistic regression analyses were to assess the risk factors of FBs presence and complications. All tests were two-tailed and $\mathrm{P}<0.05$ was defined as statistically significant. SPSS statistical software (ver. 13.0; SPSS Inc., Chicago, IL, USA) was applied to complete the statistical analyses.

\section{Results}

\section{Characteristics and risk factors of patients with foreign body ingestion}

A total of 1,311 patients with suspected FBs ingestion underwent endoscopic management and FBs were found in $1,182(90.16 \%)$ individuals. Compared to patients without $\mathrm{FB}$, those with $\mathrm{FB}$ present were of older age $(55.09 \pm 15.72$ vs. $46.70 \pm 16.22$ years, $\mathrm{P}<0.0001)$, more frequently female (61.17\% vs. $44.96 \%, \mathrm{P}<0.0001$ ), and of shorter ingestion duration (23.78 \pm 2.12 vs. $41.24 \pm 7.46$ hours, $\mathrm{P}=0.014)$.

Significant variables that estimated the presence of FBs based on Pearson's Chi-square tests included gender, age, and duration of $\mathrm{FB}$ ingestion $(\mathrm{P}<0.05)$. The risk factor of $\mathrm{FBs}$ 
Table 1 Characteristics and risk factors of patients with foreign body ingestion

\begin{tabular}{|c|c|c|c|c|c|c|}
\hline Characteristics/items & $\begin{array}{l}\text { Foreign bodies present, } \\
\qquad \mathrm{n}=1,182(\%)\end{array}$ & $\begin{array}{l}\text { Foreign bodies absent, } \\
\qquad \mathrm{n}=129(\%)\end{array}$ & $P$ value & $P$ value ${ }^{b}$ (logistic) & OR & $95 \% \mathrm{Cl}$ \\
\hline Age, mean $\pm S D$ (years) & $55.09 \pm 15.72$ & $46.70 \pm 16.22$ & $<0.0001$ & 0.429 & - & - \\
\hline Impaction time (h) & $23.78 \pm 2.12$ & $41.24 \pm 7.46$ & 0.014 & - & - & - \\
\hline
\end{tabular}

$\mathrm{P}$ value ${ }^{\mathrm{a}}$ : Pearson's Chi-square test or $t$ test; $\mathrm{P}$ value ${ }^{\mathrm{b}}$ : logistic regression analysis; SD, standard deviation; OR, odds ratio; Cl, confidence interval.

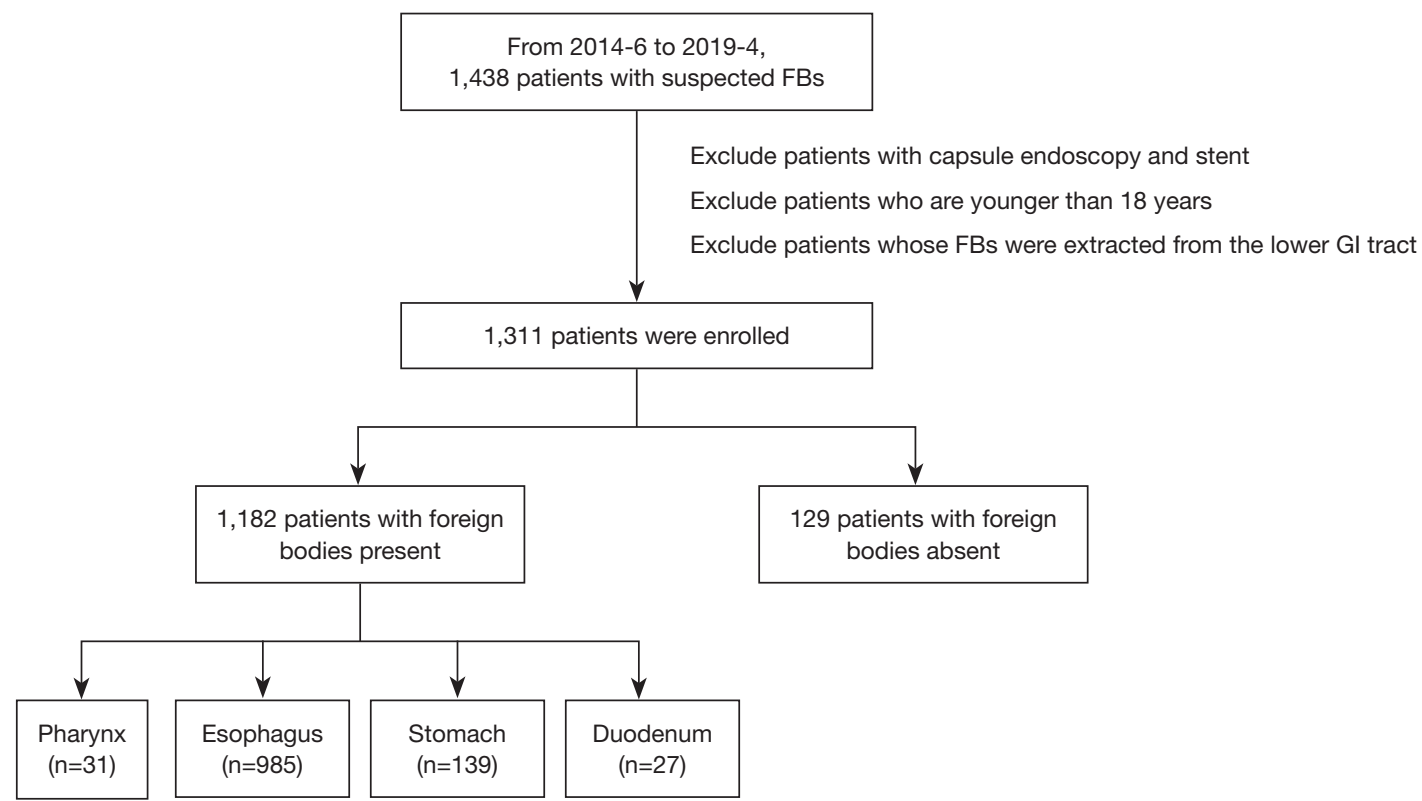

Figure 1 Gastroenterology Department flow sheet of patient with foreign body ingestion. FBs, foreign bodies.

presence was the duration less than $24 \mathrm{~h}$ (OR 3.67; 95\% CI: 2.05-6.64) via the logistic regression analysis (Table 1).

\section{The type and location of $F B$}

Various types of FBs were detected in the upper GI tract, consisting of jujube pits (36.72\%), fish bones $(22.00 \%)$, dental prostheses $(6.60 \%)$, other bones such as chicken or duck bones (10.49\%), and small metallic FBs (5.24\%) such as needles, spoons, rings, and coins, and medicine or its packaging (3.64\%). Other objects included lighters, technological products, chopsticks, plastics, nuts, shears, pens, chinaware fragments, and plastic knives (Table S1). Anatomically, most FBs were detected in the esophagus $(\mathrm{n}=985,83.33 \%)$, with the stomach $(\mathrm{n}=139,11.76 \%)$, pharynx $(\mathrm{n}=31,2.62 \%)$, and duodenum $(\mathrm{n}=27,2.28 \%)$ following (Figure 1).

\section{Types of accessory device}

The selection of tools to remove FBs mainly depends on the type and location of the FB $(21,22)$. The most frequently used devices were foreign body forceps $(70.55 \%)$, snare $(8.63 \%)$, and rat-tooth forceps $(6.77 \%)$. Others, such as biopsy forceps $(0.85 \%)$, alligator jaws forceps $(0.34 \%)$, and retrieval basket $(0.34 \%)$ were rarely adopted. Foreign body forceps (forceps) were more frequently applied in managing routine types of FBs like jujube pits (OR 5.87; 95\% CI: 3.09-11.13) or fish bones (OR 31.65; 95\% CI: 4.39-228.35). The most successful method for removing FBs was forceps 
Table 2 Type of accessory devices

\begin{tabular}{|c|c|c|c|c|}
\hline Accessory devices (No./\%) & Success rate (No./\%) & $P$ value & Location of foreign bodies ingestion/number & $P$ value \\
\hline \multirow{2}{*}{$\begin{array}{l}\text { Foreign body forceps (only) } \\
(834 / 70.55)\end{array}$} & & & Esophagus/734 & \\
\hline & & & Stomach and duodenum/77 & \\
\hline \multirow{2}{*}{ Snare (only) (102/8.63) } & $94 / 92.15$ & 0.147 & Pharynx/2 & \\
\hline & & & Stomach and duodenum/44 & $<0.0001^{1}$ \\
\hline \multirow{3}{*}{ Rat-tooth forceps (88/7.38) } & $83 / 94.32$ & 0.634 & Pharynx/6 & \\
\hline & & & Esophagus/76 & $0.653^{1}$ \\
\hline & & & Stomach and duodenum/6 & \\
\hline Alligator jaws forceps (5/0.42) & & & Stomach and duodenum/1 & \\
\hline \multirow{2}{*}{ Biopsy forceps (10/0.85) } & $9 / 90.0$ & 0.415 & Esophagus/5 & $0.004^{1}$ \\
\hline & & & Stomach and duodenum $/ 5$ & \\
\hline \multirow{3}{*}{ Retrieval basket (4/0.34) } & $3 / 75.0$ & 0.053 & Pharynx/0 & \\
\hline & & & Esophagus/3 & $0.402^{1}$ \\
\hline & & & Stomach and duodenum/1 & \\
\hline \multirow[b]{2}{*}{ Use at least 2 tools $(118 / 9.38)$} & $109 / 92.37$ & 0.155 & Pharynx/0 & \\
\hline & & & Esophagus/98 & $0.138^{1},<0.0001^{2}$ \\
\hline
\end{tabular}

${ }^{1}$, means compared to foreign body forceps; ${ }^{2}$, means compared to snare.

(796/834, 95.44\%), the application of which was higher in the esophagus compared to snare $(88.01 \%$ vs. $53.92 \%)$. Snares were used in 102 patients with $44(43.14 \%)$ cases in the stomach where their utilization was more effective than that of forceps $(43.14 \%$ vs. $9.23 \%)$ in extracting metallic objects (OR 4.51; 95\% CI: 2.67-7.64) and dental prosthesis (OR 6.35; 95\% CI: 3.42-11.83) (Tables 2,3).

\section{Endoscopy method}

All patients underwent endoscopy via topical pharyngeal anesthesia $(n=1,100)$ or general anesthesia $(n=82)$. Patients who experienced the former had a higher average age (55.64 \pm 0.47 vs. $47.84 \pm 1.80, \mathrm{P}<0.0001)$. Compared with topical approaches, removal using general endoscopy on the successful rate was higher $(96.34 \%$ vs. $92.73 \%$, $\mathrm{P}=0.225)$ and exhibited a lower complication rate $(20.55 \%$ vs. $15.85 \%, \mathrm{P}=0.308$ ) (Table 4). Unfortunately, these given data seem to disagree that endoscopic process with general anesthesia has evident superiorities.

\section{Complications of FB}

While there were no deaths, 239 patients (20.22\%) developed complications when endoscopy was used. The most frequent of these were hemorrhage $(\mathrm{n}=162,67.78 \%)$ and perforation $(\mathrm{n}=65,27.20 \%)$ as shown in Table S2. However other serious complications such as neck subcutaneous emphysema or mediastinum emphysema, esophagitis and cervical space infection or mediastinitis, rupture of large blood vessels, or esophagotracheal fistula observed in previous studies (23), were not seen in ours.

There were no differences in gender and anesthetic methods between patients with complication and without 
Table 3 Comparison of two tools for removing foreign bodies

\begin{tabular}{|c|c|c|c|c|c|}
\hline Items & $\begin{array}{l}\text { Foreign body forceps } \\
\text { (only), } n=834 / 70.55 \%\end{array}$ & $\begin{array}{c}\text { Snare (only), } \\
n=102 / 8.63 \%\end{array}$ & $P$ value ${ }^{a}$ & $\begin{array}{l}\mathrm{P} \text { value } \\
\text { (logistics) }\end{array}$ & OR; $95 \% \mathrm{Cl}$ \\
\hline Success rate & $796 / 95.44 \%$ & $94 / 92.15 \%$ & 0.147 & - & - \\
\hline \multicolumn{6}{|l|}{ Location } \\
\hline Pharynx & $20 / 2.40 \%$ & $2 / 1.96 \%$ & 1.0 & & \\
\hline \multicolumn{6}{|l|}{ The type of foreign bodies } \\
\hline Jujube pits & $346 / 41.49 \%$ & $11 / 10.78 \%$ & $<0.0001$ & $<0.0001$ & $5.87 ; 3.09-11.13$ \\
\hline Fish bone & $199 / 23.86 \%$ & $1 / 0.98 \%$ & $<0.0001$ & $<0.0001$ & $31.65 ; 4.39-228.35$ \\
\hline
\end{tabular}

$\mathrm{P}$ value ${ }^{\mathrm{a}}$ : Pearson's Chi-square test; $\mathrm{P}$ value ${ }^{\mathrm{b}}$ : logistic regression analysis. OR, odds ratio; $\mathrm{Cl}$, confidence interval.

Table 4 The method of endoscopy

\begin{tabular}{lccc}
\hline Parameters & Topical pharyngeal anesthesia $(\mathrm{n}=1,100)$ & General anesthesia $(\mathrm{n}=82)$ & $\mathrm{P}$ value \\
\hline Male & $410 / 37.27 \%$ & $49 / 59.76 \%$ & $47.84 \pm 1.80$ \\
Mean age (years) & $55.64 \pm 0.47$ & $79 / 96.34 \%$ & $<0.0001$ \\
Successful endoscopic removal & $1020 / 92.73 \%$ & $13 / 15.85 \%$ & 0.225 \\
Complications & $226 / 20.55 \%$ & 41.60 & 0.308 \\
Mean of duration of impaction (h) & 29.24 & 0.331 & \\
\hline
\end{tabular}

complication $(\mathrm{P}=0.265$ and 0.392). However, patients who experienced complications were older than those who did not $(58.71 \pm 1.43$ vs. $54.19 \pm 2.98, \mathrm{P}<0.0001)$, and the duration of $\mathrm{FB}$ presence prior to removal was significantly longer in the former $(36.43 \pm 4.22$ vs. $18.00 \pm 1.37, \mathrm{P}<0.0001)$. Interestingly, FBs were more likely to be found in the esophagus in patients with complications $(\mathrm{P}=0.028)$. Consistently, the consequence of logistics analysis showed that the independent risk factors of complications were age $\geq 60$ (OR 1.54; 95\% CI: 1.07-2.20), the presence of FBs beyond 24 h (OR 2.67; 95\% CI: 2.00-3.57), and esophageal FBs (OR 2.07; 95\% CI: 1.22-3.53) (Table 5).

\section{Discussion}

FB ingestion is a universal clinical problem. Of the 1,131 patients involved in this study FBs were found in $90.16 \%$ patients via endoscopic procedures. Complications were observed in 239 cases (20.22\%), of which hemorrhage $(162 / 239,67.78 \%)$ was the most frequent. Risk factors of complications included age $\geq 60$, duration of FB ingestion $\geq 24 \mathrm{~h}$ and esophageal FBs.

Although patients with FBs suffer symptoms such as throat discomfort, epigastric pain, vomiting, and dysphagia (14), some FBs produce no symptoms. In addition, a duration of less than $24 \mathrm{~h}$ was a possible factor indicating the presence of FBs in this study, which is consistent with previous findings that early presentation is one of the independent predictors of the presence of FBs $(15,16)$. A duration of less than $24 \mathrm{~h}$ increased the risk of the presence of FBs by a 3.67 -fold.

In our study, nearly $59 \%$ of FBs were fish bones and jujube pits, which is similar to previous findings indicating that most FB ingestions were accidental food and bone impactions (24-26). Moreover, a great majority of FBs were esophageal as also previously published $(1,17)$. Foreign 
Table 5 Risk factors for complications of foreign bodies

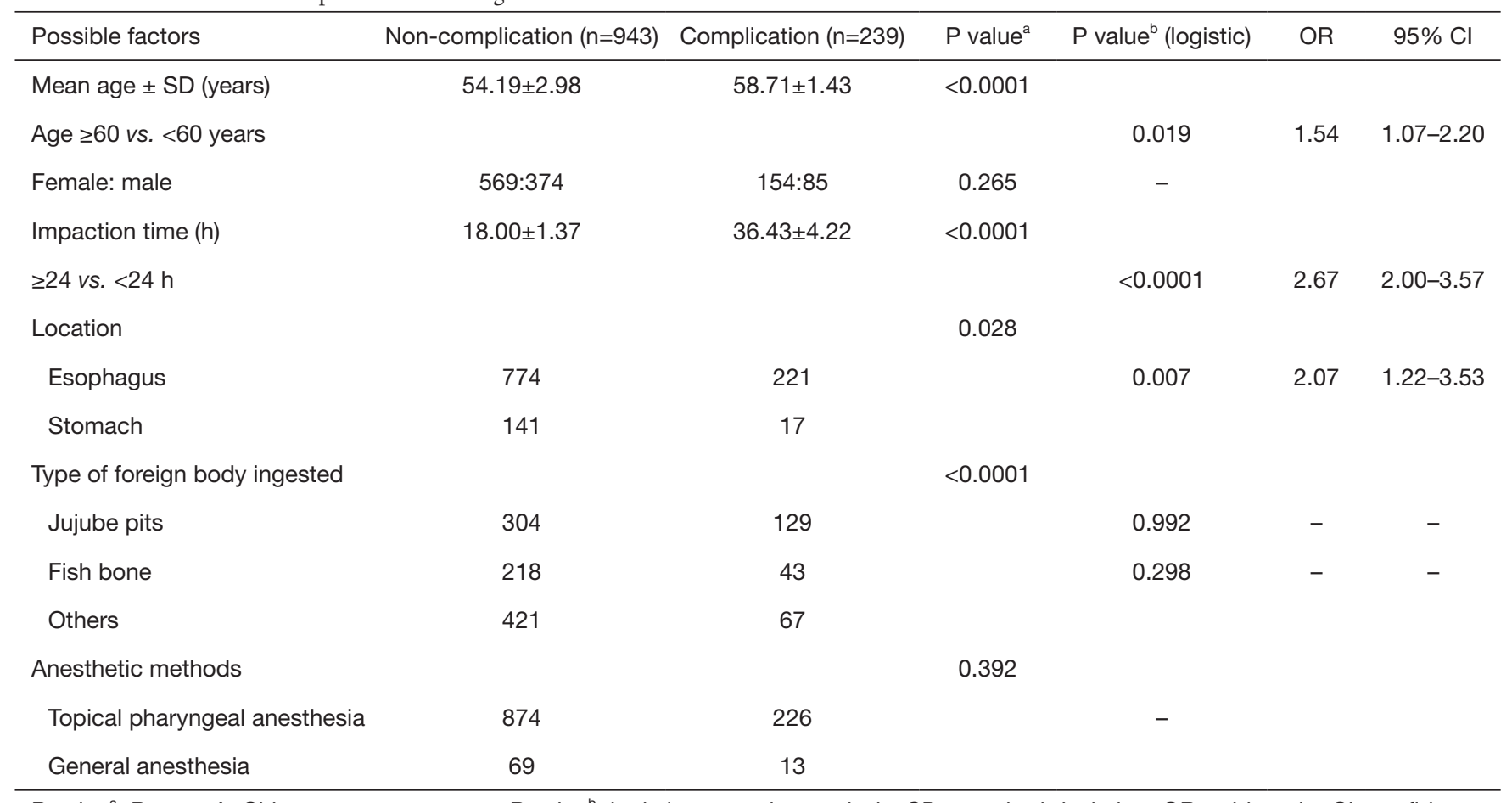

$P$ value ${ }^{a}$ : Pearson's Chi-square test or $t$-test; $\mathrm{P}$ value ${ }^{\mathrm{b}}$ : logistic regression analysis. SD, standard deviation; OR, odds ratio; $\mathrm{Cl}$, confidence interval.

bodies forceps successfully removed generous esophageal FBs including jujube pits, while snare was the best choice to remove FBs ingested in the stomach, such as dental prostheses. While our findings were largely consistent with those of Geng [2017] (17) who found no distinct differences in the success rates between general and topical pharyngeal anesthesia, our data conveyed a trend towards a lower complication rate $(15.85 \%$ vs. $20.55 \%)$ and higher removal rate $(96.34 \%$ vs. $92.73 \%)$ under general anesthesia. More research is required to determine whether these benefits of general anesthesia are more broadly apparent.

The complication rate after removal of $\mathrm{FB}$ ingestion was around $20 \%$ in our patients, although this has ranged from fewer than $5 \%$ to nearly $50 \%$ in other studies $(20,27,28)$. A possible reason for the high complication rate seen in some studies may be that mucosal injury and hematoma are classified as mild complications, appearing in up to $29.5 \%$ in one study (17). Additionally, fever $\left(\leq 38^{\circ} \mathrm{C}\right)$, abrasions, small erosions, abscesses, ulcers, and mucosal laceration have also been listed as complications (27). Agreement on the criteria by which complications are classified and their reporting would greatly improve the validity and accuracy of findings.
Risk factors for FBs ingestion leading to complications have been previously observed in relation to the types and size of FBs, duration of FBs impaction and delay in endoscopic management $(1,13,15,20)$. In our paper we also identified age $\geq 60$ and esophageal FBs as additional risk factors. A longer duration of FB ingestion is associated with a greater risk of harm. The danger of complications in cases with a duration of over $24 \mathrm{~h}$ was 2.67 -fold higher than those with a duration of less than $24 \mathrm{~h}$. Furthermore, the frequency of complications increases with age. This might be due to several factors: firstly, the swallowing function and sensation are less sensitive in the elderly than in younger adults; secondly, most patients wearing dentures are elderly; thirdly, the overall physical condition of elderly patients is weaker and less able to tolerate trauma than those younger. Esophageal FBs carried a higher risk of complications in comparison to the stomach because of the narrower lumen and thinner muscular layer.

FBs ingestion can be treated successfully and safely in more than $92 \%$ of cases in this study, which was similar to most researches (16). The factors related to a successful procedure include the compliance of patients, appropriate extraction devices, experienced endoscopists, the 
radiological evaluation, the degree of cooperation between endoscopists and nurses, and so on.

The chief limitations to this study are its retrospective nature and the uneven number of patients in the general anesthesia and endoscopy groups. Although retrospective research might increase the deviations of research results, we collected the associated data of patients with foreign bodies ingested from June 2014 and April 2019 to expand the sample size and avoid the condition. The latter result in the distribution of adverse outcomes towards the general anesthesia group. Further investigation into the benefits of general anesthesia in removing FBs is strongly recommended.

In conclusion, the duration of ingestion before removal was the common factor affecting the presence of FBs and its complications, while age $\geq 60$ and esophageal FBs were other risk factors contributing to complications. Taking these possible risk factors into consideration, appropriate endoscopic interventions could be executed to treat patients with $\mathrm{FB}$ ingestion.

\section{Acknowledgments}

We appreciate the efforts all of our colleagues have made towards in this study.

Funding: This study was supported by a grant from the National Natural Science Foundation of China (No. 81570489).

\section{Footnote}

Reporting Checklist: The authors have completed the STROBE reporting checklist. Available at http://dx.doi. org/10.21037/atm-21-829

Data Sharing Statement: Available at http://dx.doi. org/10.21037/atm-21-829

Conflicts of Interest: All authors have completed the ICMJE uniform disclosure form (available at http://dx.doi. org/10.21037/atm-21-829). The authors have no conflicts of interest to declare.

Ethical Statement: The authors are accountable for all aspects of the work in ensuring that questions related to the accuracy or integrity of any part of the work are appropriately investigated and resolved. This study was approved by the Institutional Review Board of Tianjin
Medical University General Hospital (Ethical No. IRB2020-WZ-141). All procedures performed in this study involving human participants were in accordance with the Declaration of Helsinki (as revised in 2013). Individual consent for this retrospective analysis was waived.

Open Access Statement: This is an Open Access article distributed in accordance with the Creative Commons Attribution-NonCommercial-NoDerivs 4.0 International License (CC BY-NC-ND 4.0), which permits the noncommercial replication and distribution of the article with the strict proviso that no changes or edits are made and the original work is properly cited (including links to both the formal publication through the relevant DOI and the license). See: https://creativecommons.org/licenses/by-nc-nd/4.0/.

\section{References}

1. Hong KH, Kim YJ, Kim JH, et al. Risk factors for complications associated with upper gastrointestinal foreign bodies. World J Gastroenterol 2015;21:8125-31.

2. Mowry JB, Spyker DA, Cantilena LR, et al. 2013 Annual Report of the American Association of Poison Control Centers' National Poison Data System (NPDS):31st Annual Report. Clin Toxicol (Phila) 2014;52:1032-283.

3. Long B, Koyfman A, Gottlieb M. Esophageal Foreign Bodies and Obstruction in the Emergency Department Setting: An Evidence-Based Review. J Emerg Med 2019;56:499-511.

4. Geraci G, Sciume' C, Di Carlo G, et al. Retrospective analysis of management of ingested foreign bodies and food impactions in emergency endoscopic setting in adults. BMC Emerg Med 2016;16:42.

5. Bekkerman M, Sachdev AH, Andrade J, et al. Endoscopic Management of Foreign Bodies in the Gastrointestinal Tract: A Review of the Literature. Gastroenterol Res Pract 2016;2016:8520767.

6. Smith MT, Wong RK. Esophageal foreign bodies: types and techniques for removal. Curr Treat Options Gastroenterol 2006;9:75-84.

7. Birk M, Bauerfeind P, Deprez PH, et al. Removal of foreign bodies in the upper gastrointestinal tract in adults: European Society of Gastrointestinal Endoscopy (ESGE) Clinical Guideline. Endoscopy 2016;48:489-96.

8. Eisen GM, Baron TH, Dominitz JA, et al. Guideline for the management of ingested foreign bodies. Gastrointest Endosc 2002;55:802-6.

9. Ginsberg GG. Management of ingested foreign objects 
and food bolus impactions. Gastrointest Endosc 1995;41:33-8.

10. Li ZS, Sun ZX, Zou DW, et al. Endoscopic management of foreign bodies in the upper-GI tract: experience with 1088 cases in China. Gastrointest Endosc 2006;64:485-92.

11. McKechnie JC. Gastroscopic removal of a phytobezoar. Gastroenterology 1972;62:1047-51.

12. Chen Q, Chu H, Tong T, et al. Predictive factors for complications associated with penetrated fish bones outside the upper gastrointestinal tract. Eur Arch Otorhinolaryngol 2019;276:185-91.

13. Yao CC, Wu IT, Lu LS, et al. Endoscopic Management of Foreign Bodies in the Upper Gastrointestinal Tract of Adults. Biomed Res Int 2015;2015:658602.

14. Zhang S, Cui Y, Gong X, et al. Endoscopic management of foreign bodies in the upper gastrointestinal tract in South China: a retrospective study of 561 cases. Dig Dis Sci 2010;5 5:1305-12.

15. Saltiel J, Molinsky R, Lebwohl B. Predictors of Outcomes in Endoscopies for Foreign Body Ingestion: A CrossSectional Study. Dig Dis Sci 2020;65:2637-43.

16. Libânio D, Garrido M, Jácome F, et al. Foreign body ingestion and food impaction in adults: better to scope than to wait. United European Gastroenterol J 2018;6:974-80.

17. Geng C, Li X, Luo R, et al. Endoscopic management of foreign bodies in the upper gastrointestinal tract: a retrospective study of 1294 cases. Scand J Gastroenterol 2017;52:1286-91.

18. Lyons MF 2nd, Tsuchida AM. Foreign bodies of the gastrointestinal tract. Med Clin North Am 1993;77:1101-14.

19. Hung CW, Hung SC, Lee CJ, et al. Risk factors for

Cite this article as: Wang $\mathrm{X}$, Su S, Chen $\mathrm{Y}$, Wang Z, Li Y, Hou J, Zhong W, Wang Y, Wang B. The removal of foreign body ingestion in the upper gastrointestinal tract: a retrospective study of 1,182 adult cases. Ann Transl Med 2021;9(6):502. doi: 10.21037/atm-21-829 complications after a foreign body is retained in the esophagus. J Emerg Med 2012;43:423-7.

20. Sung SH, Jeon SW, Son HS, et al. Factors predictive of risk for complications in patients with oesophageal foreign bodies. Dig Liver Dis 2011;43:632-5.

21. Birk M, Bauerfeind P, Deprez PH, et al. Removal of foreign bodies in the upper gastrointestinal tract in adults: European Society of Gastrointestinal Endoscopy (ESGE) Clinical Guideline. Endoscopy 2016;48:489-96.

22. Wu WT, Chiu CT, Kuo CJ, et al. Endoscopic management of suspected esophageal foreign body in adults. Dis Esophagus 2011;24:131-7.

23. Chirica M, Champault A, Dray X, et al. Esophageal perforations. J Visc Surg 2010;147:e117-28.

24. Zhang X, Zhang X, Tu C, et al. Analysis of the management and risk factors for complications of esophageal foreign body impaction of jujube pits in adults. Wideochir Inne Tech Maloinwazyjne 2018;13:250-6.

25. Gretarsdottir HM, Jonasson JG, Björnsson ES. Etiology and management of esophageal food impaction: a population based study. Scand J Gastroenterol 2015;50:513-8.

26. Zhong Q, Jiang R, Zheng X, et al. Esophageal foreign body ingestion in adults on weekdays and holidays: A retrospective study of 1058 patients. Medicine (Baltimore) 2017;96:e8409.

27. Weiland ST, Schurr MJ. Conservative management of ingested foreign bodies. J Gastrointest Surg 2002;6:496-500.

28. Kim JE, Ryoo SM, Kim YJ, et al. Incidence and Clinical Features of Esophageal Perforation Caused by Ingested Foreign Body. Korean J Gastroenterol 2015;66:255-60.

(English Language Editor: B. Draper) 
Supplementary

Table S1 The type of foreign bodies

\begin{tabular}{lcc}
\hline Type & Number & Percentage (\%) \\
\hline Jujube pits & 434 & 36.72 \\
Fish bone & 260 & 22.00 \\
Other bone & 124 & 10.49 \\
Dental prosthesis & 78 & 6.60 \\
Metallic & 62 & 5.24 \\
Medicine or its packaging & 43 & 3.64 \\
Others & 181 & 15.31 \\
Total & 1182 & 100 \\
\hline
\end{tabular}

Table S2 The type of complications

\begin{tabular}{lcc}
\hline Type of complications & Number & Percent (\%) \\
\hline Hemorrhage & 162 & 67.78 \\
Perforation & 65 & 27.20 \\
Perforation with bleeding & 12 & 5.02 \\
Total & 239 & 100 \\
\hline
\end{tabular}

